Article

\title{
Numerical Study of Elasto-Plastic Hydraulic Fracture Propagation in Deep Reservoirs Using a Hybrid EDFM-XFEM Method
}

\author{
Wenzheng Liu ${ }^{1}$, Qingdong Zeng ${ }^{2}$, Jun Yao ${ }^{1, *}$, Ziyou Liu ${ }^{1}$, Tianliang Li ${ }^{3}$ and Xia Yan ${ }^{1}$ \\ 1 Research Center of Multiphase Flow in Porous Media, China University of Petroleum (East China), \\ Qingdao 266580, China; b17020087@s.upc.edu.cn or upc_lwz@163.com (W.L.); s19020135@s.upc.edu.cn (Z.L.); \\ b14020069@s.upc.edu.cn (X.Y.) \\ 2 Department of Mechanics, Shandong University of Science and Technology, Qingdao 266580, China; \\ zengqingdong@sdust.edu.cn \\ 3 Production Optimization R\&D Institute of COSL, Tianjin 300459, China; lit17@cosl.com.cn \\ * Correspondence: rocgfr_upc@126.com
}

check for updates

Citation: Liu, W.; Zeng, Q.; Yao, J.;

Liu, Z.; Li, T.; Yan, X. Numerical Study of Elasto-Plastic Hydraulic Fracture Propagation in Deep Reservoirs Using a Hybrid EDFM-XFEM Method. Energies 2021, 14, 2610. https://doi.org/ $10.3390 /$ en14092610

Academic Editor: Alireza Nouri

Received: 23 February 2021

Accepted: 28 April 2021

Published: 2 May 2021

Publisher's Note: MDPI stays neutral with regard to jurisdictional claims in published maps and institutional affiliations.

Copyright: (c) 2021 by the authors. Licensee MDPI, Basel, Switzerland. This article is an open access article distributed under the terms and conditions of the Creative Commons Attribution (CC BY) license (https:/ / creativecommons.org/licenses/by/ $4.0 /)$.

\begin{abstract}
Rock yielding may well take place during hydraulic fracturing in deep reservoirs. The prevailing models based on the linear elastic fracture mechanics (LEFM) are incapable of describing the evolution process of hydraulic fractures accurately. In this paper, a hydro-elasto-plastic model is proposed to investigate the hydraulic fracture propagation in deep reservoirs. The Drucker-Prager plasticity model, Darcy's law, cubic law and cohesive zone model are employed to describe the plastic deformation, matrix flow, fracture flow and evolution of hydraulic fractures, respectively. Combining the embedded discrete fracture model (EDFM), extended finite element method (XFEM) and finite volume method, a hybrid numerical scheme is presented to carry out simulations. A dual-layer iterative procedure is developed based on the fixed-stress split method, Picard iterative method and Newton-Raphson iterative method. The iterative procedure is used to deal with the coupling between nonlinear deformation with fracture extension and fluid flow. The proposed model is verified against analytical solutions and other numerical simulation results. A series of numerical cases are performed to investigate the influences of rock plasticity, internal friction angle, dilatancy angle and permeability on hydraulic fracture propagation. Finally, the proposed model is extended to simulate multiple hydraulic fracture propagation. The result shows that plastic deformation can enhance the stress-shadowing effect.
\end{abstract}

Keywords: hydraulic fracture; deep reservoir; rock plasticity; cohesive zone model; embedded discrete fracture model; extended finite element method

\section{Introduction}

With the rapid growth in the global demand for oil and gas resources and the successful development of middle-shallow formations $(<4500 \mathrm{~m})$, the exploitation of oil and gas reservoirs is gradually extended to the deep formations (>4500 m) [1,2]. Hydraulic fracturing technology, which can effectively improve the permeability of reservoir rocks, plays an important role in the development of oil and gas reservoirs [3]. It is important to predict the shape and trend of hydraulic fractures accurately. However, as deep reservoirs are characterized by high pressure, high temperature and high stress, the rock brittleness decreases and nonlinear deformation becomes obvious [4,5]. The prevailing fracture propagation models based on the linear elastic fracture mechanics are no longer applicable for predicting the evolution process of hydraulic fractures in deep ductile formations. Accounting for rock plasticity, establishing an efficient model to perform accurate simulation of hydraulic fracture propagation is significant for the development of deep oil and gas resources. 
In the past decades, quite a few research works on hydraulic fracture propagation have been conducted, which can be roughly divided into three stages. In the first stage (1960s-1970s), researchers mainly focused on analytical models and solutions for the twodimensional hydraulic fracture, such as the classical KGD model [6,7] and PKN [8,9] model. In the second stage (1980s-1990s), on the basis of 2D fracture models, many quasi-3D and true-3D models $[10,11]$ were presented. In the third stage (since the 1990s), with increasing complexity of problems and the development of computer technology, numerical models gradually replaced analytical models for the study of fluid-driven fracture propagation due to the limitations of analytical models. For hydraulic fracturing simulation, a key issue is to solve the discontinuous fields, including the displacement and pressure fields. Numerical methods usually used to simulate the fields with discontinuities are as follows: the finite element method [12,13], extended finite element method [14], discontinuous displacement method [15,16], distinct element method [17,18], discrete element model [19], lattice element model [20], discrete fracture network [21,22], and embedded discrete fracture model [23]. Their advantages and disadvantages are detailed in the literatures [24,25]. In the above methods, the XFEM allows fracture growth across the grid without remeshing, so it is widely used to solve discontinuous displacement fields. In addition, the EDFM, in which the fracture is embedded in non-matching grids, is usually employed to model the fluid flow between the fractures and the matrix in fractured formation. In this paper, the XFEM and EDFM are adopted to model the discontinuous displacement and pressure fields, respectively. Combined with the common advantages of the two, the limitations of the mesh size and shape on hydraulic fracturing simulation are relieved.

In most available fracture models, the rock is assumed to be linear elastic media. Few research works focus on hydraulic fracture propagation in elasto-plastic media. On the basis of the Mohr-Coulomb yielding theory, Papanastasiou [26] built an efficient cohesive finite element model to simulate hydraulic fracture propagation in inelastic media. Combining the extended finite element method and the cohesive zone model, Liu [27] developed a stabilized model to simulate hydraulic fracture propagation in brittle and ductile formations. Zeng [28] studied the effects of plastic deformation on fluid-driven fracture extension with the Drucker-Prager yield criterion. Liu [23] presented an efficient numerical model for elasto-plastic hydraulic fracture extension considering thermal effects. However, in these studies, fluid flow in the matrix is ignored by assuming an impermeable rock material, which has been proven to be an unrealistic assumption by considerable field evidence [29]. Sarris [30] added the seepage flow to Papanastasiou's model. Wang [31] carried out poro-elastic and poro-plastic modeling of hydraulic fracturing in brittle and ductile formations with the finite element method (FEM). In both studies of Sarris and Wang, a fully coupling solution method was adopted to conduct numerical simulations, which needed huge computational costs. Besides, in those studies mentioned above, only the simulation of straight hydraulic fracture extension was studied. In this work, the proposed model can simulate planar or non-planar elasto-plastic hydraulic fracture propagation in non-matching grids without remeshing.

In our previous studies, combining the XFEM and EDFM, multiphase flow in deformational fractured shale reservoirs was simulated [32,33]. Then, the hybrid EDFM-XFEM method was proposed to build an efficient hydro-mechanical model of hydraulic fracture propagation in brittle [34] and anisotropic [35] formations. In this work, to study fracture propagation in deep reservoirs, we extend the model to ductile formations accounting for the rock plasticity, and construct a dual-layer iterative procedure for solving the nonlinear problem caused by inelasticity and fracture propagation.

\section{Mathematical Model}

We consider the problem that a hydraulic fracture propagates in the deep reservoir, as shown in Figure 1. The reservoir is assumed as an isotropic and homogeneous porous media. Moreover, plastic deformation of the rock is taken into account. The mathematical 
model of this problem includes the following three components: (i) rock deformation, (ii) fluid flow, and (iii) propagation criterion.

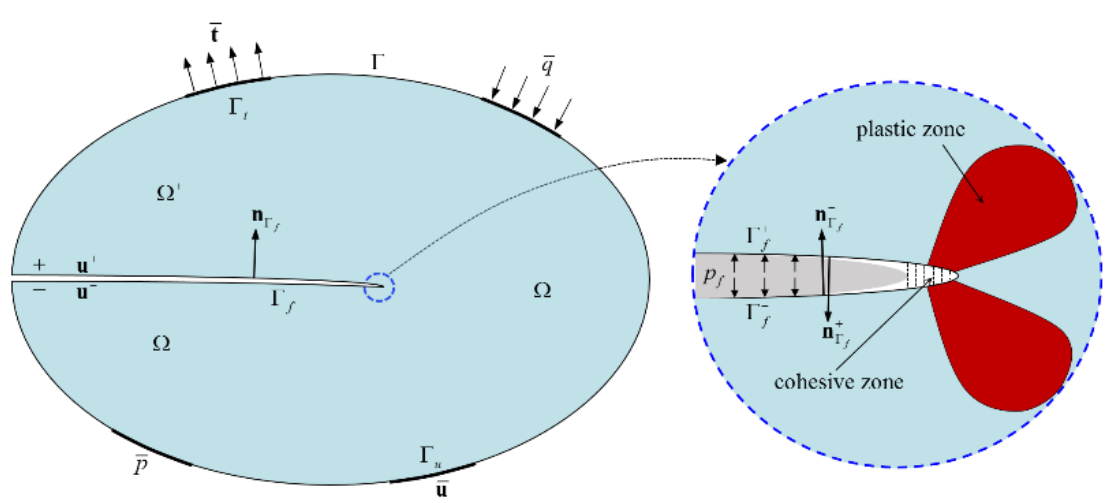

Figure 1. Physical model of elasto-plastic hydraulic fracture propagation in deep reservoirs.

\subsection{Rock Deformation}

The governing equations of rock deformation include the equilibrium equation, geometric equation and constitutive equation. The equilibrium equation is written as follows:

$$
\nabla \cdot \boldsymbol{\sigma}+\mathbf{f}=0
$$

where $\boldsymbol{\sigma}$ is the total stress tensor and $\mathbf{f}$ is the body force vector.

According to Biot's theory, effective stress can be expressed as the following [36]:

$$
\boldsymbol{\sigma}^{\prime}=\boldsymbol{\sigma}+\alpha p_{m} \mathbf{I}
$$

where $\sigma^{\prime}$ is the effective stress; $p_{m}$ is the fluid pressure in the matrix; and $\alpha$ is the Biot coefficient.

The geometric equation is written as follows:

$$
\varepsilon=\frac{1}{2}\left(\nabla \mathbf{u}+\nabla \mathbf{u}^{T}\right)
$$

where $\varepsilon$, and $\mathbf{u}$ denote the strain and displacement, respectively.

For the description of plastic deformation, the constitutive equation is characterized by the Drucker-Prager plastic theory. The yielding function is written as follows [37]:

$$
F=a I_{1}+\sqrt{J_{2}}-k=0
$$

where $I_{1}$ and $J_{2}$ represent the first invariant of the stress tensor and the second invariant of the deviatoric stress tensor, respectively, and $a$ and $k$ are the constants, expressed as the following:

$$
a=\frac{2 \sin \varphi}{\sqrt{3}(3+\sin \varphi)}, k=\frac{6 c \cos \varphi}{\sqrt{3}(3+\sin \varphi)}
$$

in which $c$ and $\varphi$ are the rock cohesion and internal friction angle, respectively.

Based on the non-associated flow rule, the constitutive relationship can be expressed in the incremental form as follows:

$$
\mathrm{d} \boldsymbol{\sigma}^{\prime}=\left[\mathbf{D}_{e}-\frac{\mathbf{D}_{e}\left[\frac{\partial Q}{\partial \boldsymbol{\sigma}^{\prime}}\right]\left[\frac{\partial F}{\partial \boldsymbol{\sigma}^{\prime}}\right]^{T} \mathbf{D}_{e}}{A+\left[\frac{\partial F}{\partial \boldsymbol{\sigma}^{\prime}}\right]^{T} \mathbf{D}_{e}\left[\frac{\partial Q}{\partial \boldsymbol{\sigma}^{\prime}}\right]}\right] \mathrm{d} \varepsilon=\mathbf{D}_{e p} \mathrm{~d} \varepsilon
$$

where $\mathbf{D}$ and $\mathbf{D}_{e p}$ represent the elastic and elasto-plastic stiffness tensor, respectively; $\mathbf{Q}$ denotes the flow potential; and A denotes the hardening parameter, which is set to be 0 in 
this paper. More details about the Drucker-Prager yielding criterion and the derivation of elasto-plastic constitutive relation can be found in our previous paper [23].

\subsection{Fluid Flow}

Fluid flow can be divided into the following three parts: flow in the matrix, flow in the fracture and the leak-off between them. The EDFM is adopted to characterize the fluid flow process. For matrix flow, the mass conservation equation can be written as follows:

$$
\nabla \cdot\left(\mathbf{v}_{m}\right)+\frac{1}{M} \frac{\partial p_{m}}{\partial t}+\alpha \frac{\partial \varepsilon_{v}}{\partial t}=\delta_{m f} \frac{q_{m f}}{S_{m}}
$$

where $\varepsilon_{v}$ is the volumetric strain; $M$ is Biot's modulus; $q_{m f}$ is the leak-off flow; $S_{m}$ is the area of the matrix gird; and $\mathbf{v}_{m}$ is the fluid flow velocity described by Darcy's law, expressed by the following:

$$
\mathbf{v}_{m}=-\frac{k_{m}}{\mu} \nabla p_{m}
$$

in which $k_{m}$ and $\mu$ denote the matrix permeability and fluid viscosity, respectively.

For fluid flow in the fracture, the mass conservation equation with consideration of the fracture width variation can be written as follows:

$$
\nabla \cdot\left(v_{f} w_{f}\right)+\frac{\partial w_{f}}{\partial t}+\frac{q_{m f}}{l_{m f}}=q_{f}
$$

where $l_{m f}$ is the length of the fracture grid; $w_{f}$ is the width of the fracture; and $v_{f}$ denotes the average fracture flow velocity, which can be given as the following:

$$
v_{f}=-\frac{w_{f}^{2}}{12 \mu} \nabla p_{f}
$$

In addition, based on the EDFM, the leak-off flow can be calculated by the following:

$$
q_{m f}=\frac{2 k_{m} l_{m f}}{\mu} \frac{p_{f}-p_{m}}{d_{m f}}=\frac{2 k_{m} l_{m f}}{\mu d_{m f}}\left(p_{f}-p_{m}\right)
$$

where $d_{m f}$ denotes the equivalent distance from the matrix element to the fracture segment [32], expressed as the following:

$$
d_{m f}=-\frac{\int x_{n} \mathrm{~d} S}{S_{m}}
$$

in which $x_{n}$ represents the vertical distance from any one point in the matrix element to the fracture segment.

\subsection{Cohesive Zone Model}

Due to the plastic deformation of deep rocks, the fracture propagation criteria based on the LEFM, including the maximum circumferential stress criteria and J integrals, are no longer applicable for deep formations. The cohesive zone model is considered to be the most reliable propagation criterion in nonlinear mechanics [24,38], and it can be easily used with the FEM [39] and XFEM [40]. Here, the cohesive zone model is employed to describe the process of fracture propagation. In the cohesive zone model, the hydraulic fracture is decomposed into the following three zones: (i) non-damage zone, (ii) fracture process zone, and (iii) broken zone, as illustrated in Figure 2a. The bilinear traction-separation model is employed to describe the relationship between the traction and displacement jumps across the fracture. As shown in Figure $2 b, \mathbf{t}_{c}$ is the cohesive traction in the following: $\mathbf{t}_{c}$ $=\left\{t_{n}, t_{s}\right\}^{T}$, in which $t_{n}$ and $t_{s}$ refer to the normal and shear components, respectively; $\mathbf{u}$ is the separation in the following: $\mathbf{u}=\mathbf{u}^{+}-\mathbf{u}^{-}$. The area under the traction-separation curve 
equals the critical strain energy rate $G_{C}$. The constitutive law of the cohesive zone model can be expressed as the following [41]:

$$
d \mathbf{t}_{c}=\mathbf{T} d \mathbf{u}
$$

where $\mathbf{T}$ is the tangential stiffness matrix of the traction-separation law.

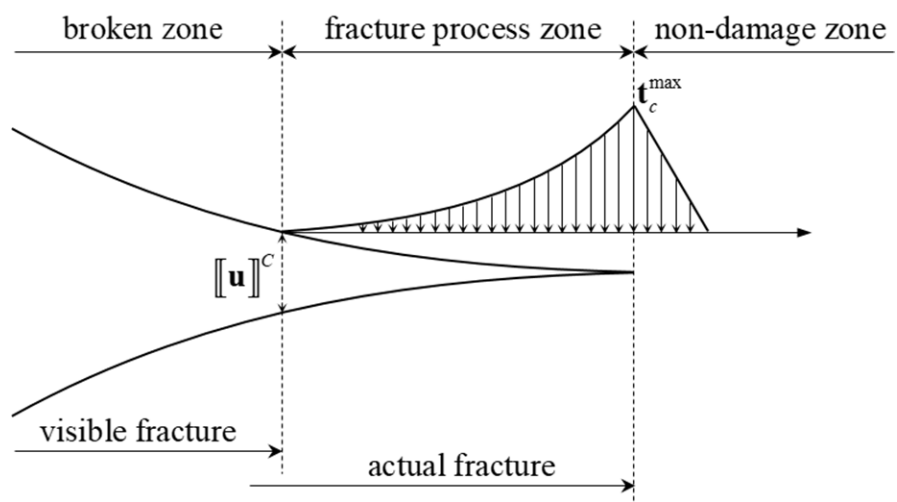

(a)

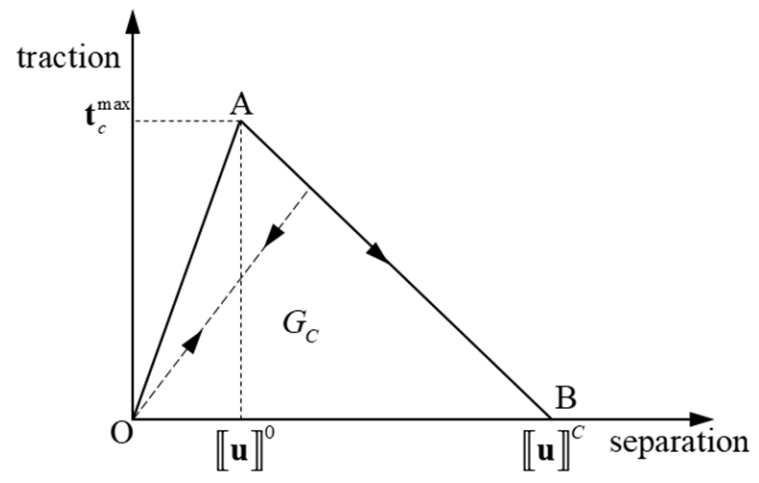

(b)

Figure 2. Diagram of the cohesive zone model. (a) Cohesive zone, and (b) bilinear cohesive law.

\section{Numerical Implementation}

In this section, the mathematical model is discretized based on the XFEM, EDFM and FVM. Besides, combining the fixed-stress split method, Picard iterative method and Newton-Raphson iterative method, a dual-layer iterative procedure is established to solve the strongly nonlinear discretized equations. Based on the proposed numerical scheme, the numerical simulations in the subsequent part are conducted by the mathematics software MATLAB.

\subsection{Displacement Field}

The XFEM is adopted to simulate the inelastic stress field with the discontinuity based on the incremental theory. According to the XFEM, at each loading step, the expression of the incremental displacement field is written as follows:

$$
\Delta u(\mathbf{x})=\sum_{i \in I} N_{i}(\mathbf{x}) \Delta \bar{u}_{i}+\sum_{j \in I^{\text {enr }}} N_{j}(\mathbf{x})\left(H\left(\varphi^{n}(\mathbf{x})\right)-H\left(\varphi^{n}\left(\mathbf{x}_{j}\right)\right)\right) \Delta \widetilde{u}_{j}
$$

where $\Delta \bar{u}_{i}, \Delta \widetilde{u}_{j}$ denote the standard and enriched nodal displacement increments, respectively; $N$ is the shape function; and $\left.H^{*}\right)$ is the Heaviside function. For writing convenience, the Equation (14) can be simplified as follows:

$$
\Delta \mathbf{u}=\mathbf{N} \Delta \overline{\mathbf{u}}+\mathbf{N}^{e n r} \Delta \tilde{\mathbf{u}}
$$

Accordingly, the incremental strain vector can be given as follows:

$$
\Delta \varepsilon=\mathbf{B} \Delta \overline{\mathbf{u}}+\mathbf{B}^{e n r} \Delta \tilde{\mathbf{u}}
$$

where $\mathbf{B}$ and $\mathbf{B}^{e n r}$ denote the derivatives of the shape function matrices $\mathbf{N}$ and $\mathbf{N}^{\text {enr }}$, respectively.

Using the Galerkin method, the weak form of Equation (1) can be obtained as follows:

$$
\int_{\Omega} \nabla(\Delta \mathbf{u}): \boldsymbol{\sigma}^{\prime} \mathrm{d} \Omega-\int_{\Omega} \nabla(\Delta \mathbf{u}): \alpha p_{m} \mathbf{I d} \Omega+\int_{\Gamma_{f}} \Delta \mathbf{u} \cdot\left(\mathbf{t}_{c}-p_{f} \mathbf{n}_{f}\right) \mathrm{d} \Gamma=\int_{\Gamma_{o}} \Delta \mathbf{u} \cdot \overline{\mathbf{t}} \mathrm{d} \Gamma+\int_{\Omega} \Delta \mathbf{u} \cdot \mathbf{f} \mathrm{d} \Omega
$$


Based on the incremental method, the following applies:

$$
(*)_{k+1}=(*)_{k}+\Delta(*) \quad\left(*=\sigma^{\prime}, \mathbf{t}_{c}, p_{f}, \overline{\mathbf{t}}, \mathbf{f}\right)
$$

where subscript $k$ denotes the loading step. Substituting Equation (18) into (17), the NewtonRaphson iterative form of the discretized system for solving incremental displacements can be obtained as follows:

$$
\left(\begin{array}{c}
\mathbf{K}_{\overline{u u}} \mathbf{K}_{\bar{u} \widetilde{u}} \\
\mathbf{K}_{\tilde{u} \bar{u}} \mathbf{K}_{\tilde{u} \widetilde{u}}
\end{array}\right)\left[\begin{array}{c}
\Delta \overline{\mathbf{u}} \\
\Delta \tilde{\mathbf{u}}
\end{array}\right]=\left(\begin{array}{c}
\Delta \mathbf{F}_{\bar{u}} \\
\Delta \mathbf{F}_{\widetilde{u}}
\end{array}\right)+\left(\begin{array}{c}
\mathbf{F}_{\bar{u}, k}^{e x t} \\
\mathbf{F}_{\widetilde{u}, k}^{e x t}
\end{array}\right)-\left(\begin{array}{c}
\mathbf{F}_{\bar{u}, k}^{i n t} \\
\mathbf{F}_{\tilde{u}, k}^{i n t}
\end{array}\right)+\left(\begin{array}{c}
\mathbf{Q}_{\bar{u} p} \\
\mathbf{Q}_{\tilde{u} p}
\end{array}\right)
$$

in which $\mathbf{K}$ and $\mathbf{Q}$ denote the stiffness matrix and coupling matrix, respectively; $\Delta \mathbf{F}, \mathbf{F}^{\text {ext }}$ and $\mathbf{F}^{\text {int }}$ denote, respectively, the incremental, external and internal force vector, expressed as the following:

$$
\begin{aligned}
& \left(\begin{array}{l}
\mathbf{K}_{\overline{u u}} \mathbf{K}_{\tilde{u} \widetilde{u}} \\
\mathbf{K}_{\widetilde{u} \bar{u}} \mathbf{K}_{\tilde{u} \widetilde{u}}
\end{array}\right)=\left(\begin{array}{cc}
\int_{\Omega} \mathbf{B}^{T} \mathbf{D}_{e p} \mathbf{B} \mathrm{d} \Omega & \int_{\Omega} \mathbf{B}^{T} \mathbf{D}_{e p} \mathbf{B}^{e n r} \mathrm{~d} \Omega \\
\int_{\Omega}\left(\mathbf{B}^{e n r}\right)^{T} \mathbf{D}_{e p} \mathbf{B} \mathrm{d} \Omega & \int_{\Omega}\left(\mathbf{B}^{e n r}\right)^{T} \mathbf{D}_{e p} \mathbf{B}^{e n r} \mathrm{~d} \Omega+\int_{\Gamma_{f}}\left(\mathbf{N}_{f}\right)^{T} \mathbf{T N}_{f} \mathrm{~d} \Gamma
\end{array}\right) \\
& \left(\begin{array}{c}
\Delta \mathbf{F}_{\bar{u}} \\
\Delta \mathbf{F}_{\widetilde{u}}
\end{array}\right)=\left(\begin{array}{c}
\int_{\Gamma_{o}} \mathbf{N}^{T} \Delta \overline{\mathbf{t}} \mathrm{d} \Gamma+\int_{\Omega} \mathbf{N}^{T} \Delta \mathbf{f} \mathrm{d} \Omega \\
\int_{\Gamma_{0}}\left(\mathbf{N}^{e n r}\right)^{T} \Delta \overline{\mathbf{t}} \mathrm{d} \Gamma+\int_{\Omega}\left(\mathbf{N}^{e n r}\right)^{T} \Delta \mathbf{f} \mathrm{d} \Omega+\int_{\Gamma_{f}}\left(\mathbf{N}_{f}\right)^{T} \Delta p_{f} \mathbf{n}_{f} \mathrm{~d} \Gamma
\end{array}\right) \\
& \left(\begin{array}{c}
\mathbf{F}_{\bar{u}, k}^{e x t} \\
\mathbf{F}_{\bar{u}, k}^{e x t}
\end{array}\right)=\left(\begin{array}{c}
\int_{\Gamma_{o}} \mathbf{N}^{T} \overline{\mathbf{t}}_{k} \mathrm{~d} \Gamma+\int_{\Omega} \mathbf{N}^{T} \mathbf{f}_{k} \mathrm{~d} \Omega \\
\int_{\Gamma_{o}}\left(\mathbf{N}^{e n r}\right)^{T} \overline{\mathbf{t}}_{k} \mathrm{~d} \Gamma+\int_{\Omega}\left(\mathbf{N}^{e n r}\right)^{T} \mathbf{f}_{k} \mathrm{~d} \Omega-\int_{\Gamma_{f}}\left(\mathbf{N}_{f}\right)^{T} p_{f, k} \mathbf{n}_{f} \mathrm{~d} \Gamma
\end{array}\right) \\
& \left(\begin{array}{c}
\mathbf{F}_{\bar{u}, k}^{i n t} \\
\mathbf{F}_{\bar{u}, k}^{i n t}
\end{array}\right)=\left(\begin{array}{c}
\int_{\Omega} \mathbf{B}^{T} \boldsymbol{\sigma}_{k}^{\prime} \mathrm{d} \Omega \\
\int_{\Omega}\left(\mathbf{B}^{e n r}\right)^{T} \boldsymbol{\sigma}_{k}^{\prime} \mathrm{d} \Omega+\int_{\Gamma_{f}}\left(\mathbf{N}_{f}\right)^{T} \mathbf{t}_{c, k} \mathrm{~d} \Gamma
\end{array}\right) \\
& \left(\begin{array}{c}
\mathbf{Q}_{\bar{u} p} \\
\mathbf{Q}_{\widetilde{u} p}
\end{array}\right)=\left(\begin{array}{c}
\int_{\Omega} \mathbf{B}^{T} \alpha \mathbf{I d} \Omega \\
\int_{\Omega}\left(\mathbf{B}^{e n r}\right)^{T} \alpha \mathbf{I d} \Omega
\end{array}\right)\left[\mathbf{p}_{m}\right]
\end{aligned}
$$

\subsection{Pressure Field}

The finite volume method (FVM) is employed to simulate the discontinuous pressure field based on the EDFM. According to FVM, the mass conservation Equation (7) is integrated over the control volume and time, expressed as the following:

$$
\int_{\Delta t} \int_{S^{e}} \nabla \cdot\left(\mathbf{v}_{m}\right) \mathrm{d} S \mathrm{~d} t+\int_{\Delta t} \int_{S^{e}} \frac{1}{M} \frac{\partial p_{m}}{\partial t} \mathrm{~d} \mathrm{~d} d t+\int_{\Delta t} \int_{S^{e}} \alpha \frac{\partial \varepsilon_{v}}{\partial t} \mathrm{dSd} t=\iint_{\Delta t} \frac{q_{m}}{S^{e}} \frac{\delta_{m f}}{S_{m}} \mathrm{dSdt} .
$$

Applying the Gaussian divergence theorem on the first term, and using the fully implicit scheme to conduct temporal discretization, Equation (21) becomes the following:

$$
\left(\sum_{j \in \eta_{i}} \mathbf{n}_{i j} \cdot \mathbf{v}_{m}^{n+1} A_{i j}\right) \Delta t+\frac{1}{M}\left(p_{m, i}^{n+1}-p_{m, i}^{n}\right) \Delta S_{i}+\alpha\left(\varepsilon_{v, i}^{n+1}-\varepsilon_{v, i}^{n}\right) \Delta S_{i}=\left(q_{m f}^{n+1} \delta_{m f}\right) \Delta t
$$

where superscript $n$ denotes the time step. Substituting Equations (8) and (11) into (22), the discrete equation can be given as the following:start a new page without indent $4.6 \mathrm{~cm}$

$$
\sum_{j \in \eta_{i}} T_{m, i j}\left(p_{m, i}^{n+1}-p_{m, j}^{n+1}\right)+H_{m, i}\left(p_{m, i}^{n+1}-p_{m, i}^{n}\right)+R_{m, i}\left(\varepsilon_{v, i}^{n+1}-\varepsilon_{v, i}^{n}\right)=\delta_{m f} L_{m f, i}\left(p_{f, i}^{n+1}-p_{m, i}^{n+1}\right)
$$


in which the following applies:

$$
T_{f, i j}=\frac{w_{i, j}^{3}}{12 \mu d_{i j}} ; R_{f, i}=\frac{\Delta x_{i}}{\Delta t} ; w_{i, j}=\frac{w_{f, i}+w_{f, j}}{2}
$$

Similarly, the discrete form of fluid flow in the fracture can be obtained as follows:

$$
\left(\sum_{j \in \eta_{i}} T_{f, i j}+L_{m f, i}\right) p_{f, i}^{n+1}-\sum_{j \in \eta_{i}} T_{f, i j} p_{f, j}^{n+1}-L_{m f, i} p_{m, i}^{n+1}=-R_{f, i}\left(w_{f, i}^{n+1}-w_{f, i}^{n}\right)+\Delta x_{i} q_{f, i}
$$

in which the following applies:

$$
T_{f, i j}=\frac{w_{i, j}^{3}}{12 \mu d_{i j}} ; R_{f, i}=\frac{\Delta x_{i}}{\Delta t} ; w_{i, j}=\frac{w_{f, i}+w_{f, j}}{2} .
$$

Therefore, the final discrete scheme can be written in the form of the matrix as follows:

$$
\left[\begin{array}{cc}
T_{m}+H_{m}+L_{m f} & -L_{m f} \\
-L_{m f} & T_{f}+L_{m f}
\end{array}\right]\left[\begin{array}{c}
p_{m}^{n+1} \\
p_{f}^{n+1}
\end{array}\right]=\left[\begin{array}{c}
r_{p}+r_{u} \\
r_{w}+r_{q}
\end{array}\right]
$$

in which the following applies:

$$
r_{p}=\frac{1}{M} \frac{\Delta S}{\Delta t} p_{m}^{n} ; r_{u}=\alpha \frac{\Delta S}{\Delta t}\left(\nabla \cdot \mathbf{u}_{m}^{n+1}-\nabla \cdot \mathbf{u}_{m}^{n}\right) ; r_{w}=-\frac{\Delta x}{\Delta t}\left(w_{f}^{n+1}-w_{f}^{n}\right) ; r_{q}=\Delta x q_{f} .
$$

\subsection{Iterative Procedure}

The nonlinearity of the established model is manifested in the following two aspects: (1) hydro-mechanical coupling and (2) the rock inelastic stress-strain relationship, which means that the solution involves two levels of the iterative process. Accordingly, a duallayer iterative procedure is built up for solving this strong nonlinear problem.

In the first layer, combining the Picard iterative method and fixed-stress split method, a global iterative algorithm is constructed to deal with nonlinear problems caused by the coupling of rock deformation and fluid flow, as shown in Figure 3. The fixed-stress split method was proved to be unconditionally stable [42] and robust for highly nonlinear problems [43]. Here, it is used to deal with a hydro-mechanical coupling problem. In accordance with the fixed-stress split method, volume strain is written as follows:

$$
\varepsilon_{v}=\frac{\sigma_{v}+\alpha p_{m}}{K_{s}} .
$$

Substituting Equation (29) into (25), after some manipulations, the fixed-stress iterative scheme of conservation in Equation (7) can be given as follows:

$$
\begin{gathered}
\left(\sum_{j \in \eta_{i}} T_{m, i j}+H_{m, i}+C_{m, i}+\delta_{m f} L_{m f, i}\right) p_{m, i}^{n+1, l+1}-\sum_{j \in \eta_{i}} T_{m, i j} p_{m, j}^{n+1, l+1}-\delta_{m f} L_{m f, i} p_{f, i}^{n+1, l+1} \\
=C_{m, i} p_{m, i}^{n+1, l}+H_{m, i} p_{m, i}^{n}-R_{m, i}\left(\nabla \cdot \mathbf{u}_{m, i}^{n+1, l}-\nabla \cdot \mathbf{u}_{m, i}^{n}\right)
\end{gathered}
$$




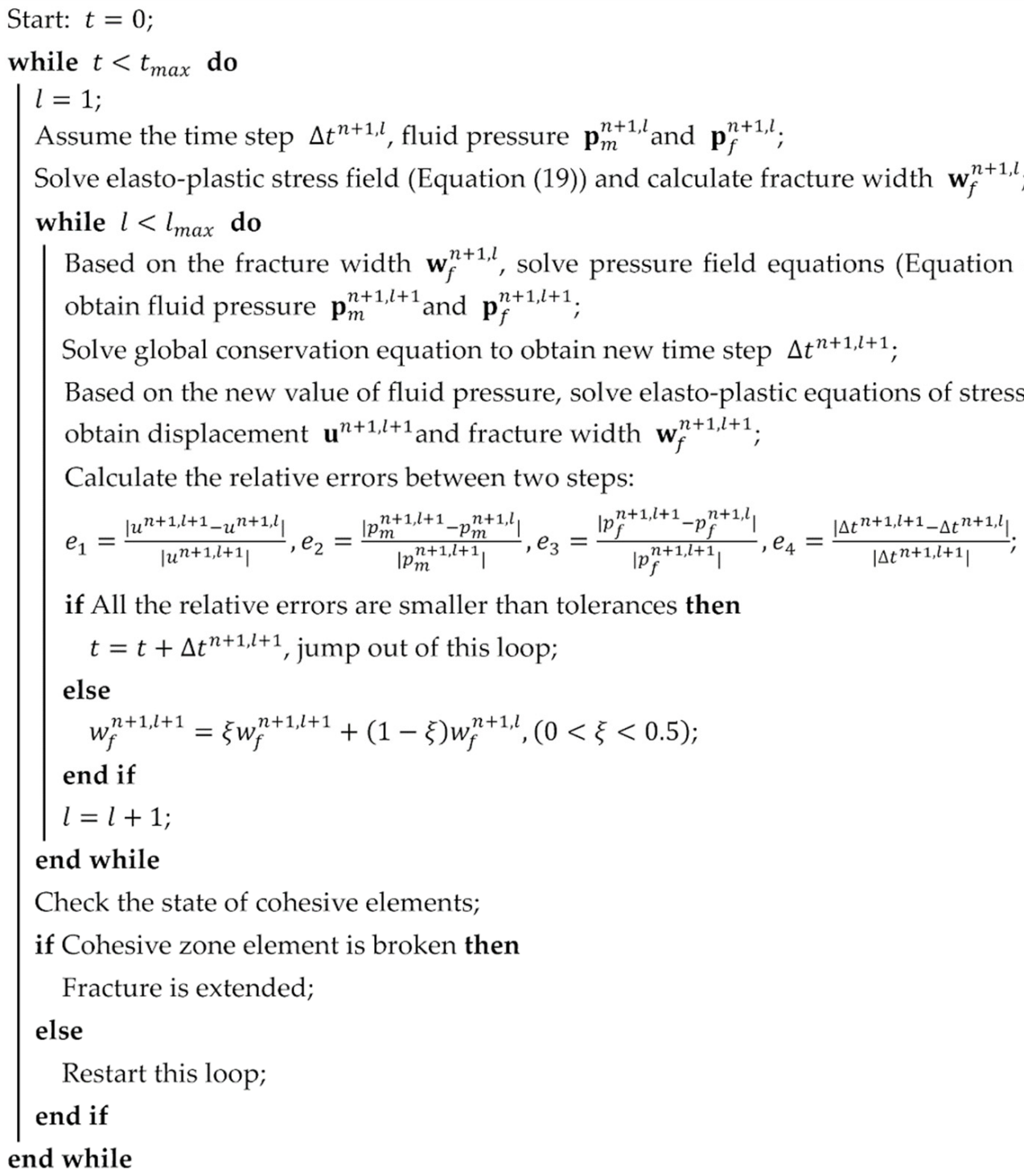

Figure 3. Overall iterative procedure for hydraulic fracture propagation.

Thus, the final discrete scheme (Equation (27)) can be derived as follows:

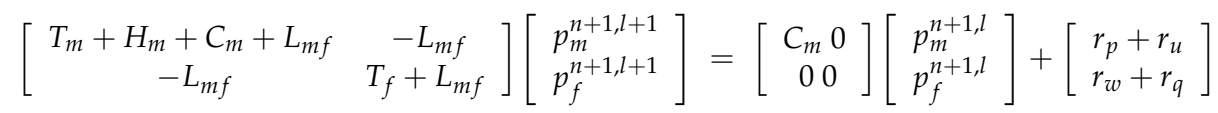

in which the following applies:

$$
C_{m, i}=\frac{\alpha^{2}}{K_{s}} \frac{\Delta V_{i}}{\Delta t} ; r_{u}=\alpha \frac{\Delta S}{\Delta t}\left(\nabla \cdot \mathbf{u}_{m}^{n+1, l}-\nabla \cdot \mathbf{u}_{m}^{n}\right) ; r_{w}=-\frac{\Delta x}{\Delta t}\left(w_{f}^{n+1, l}-w_{f}^{n}\right) .
$$

The Picard iterative method [29] is employed to handle the coupling problem between the fracture flow and varying width at every time step. If the convergence criterion is not satisfied, the fracture width is modified at each iteration step. The fluid pressure is recalculated with the modified fracture width from the previous iteration step. The convergence criterion is checked again after computing the new displacement based on the fluid pressure. 
In the second layer, as illustrated in Figure 4, the nonlinear stress field Equation (19) is solved by the Newton-Raphson iterative algorithm, in which the stress state is updated by an implicit elastic predictor and a plastic corrector return-mapping scheme $[37,44]$.

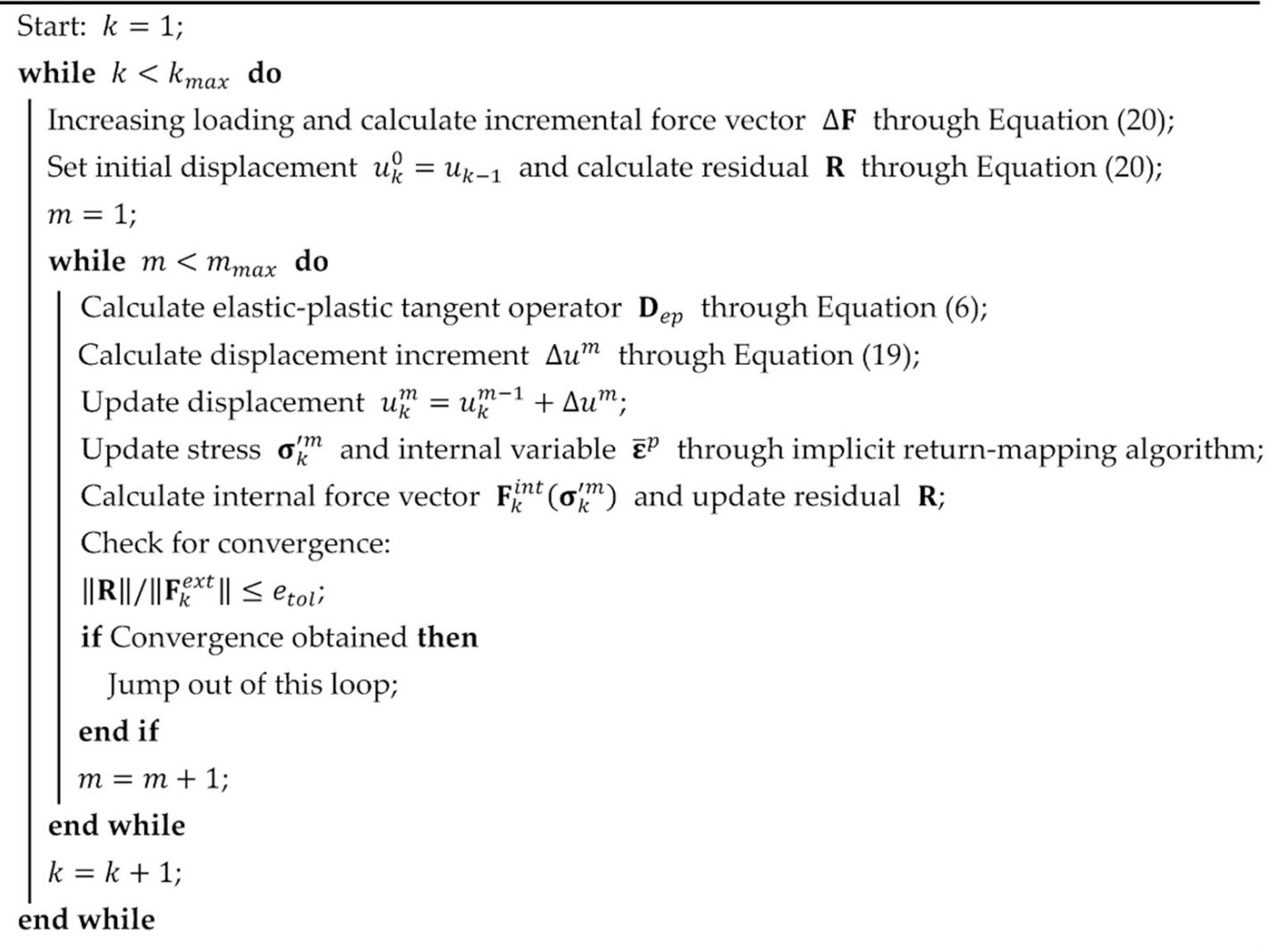

Figure 4. Overview of the iterative algorithm for solving nonlinear stress field.

\section{Numerical Results and Discussion}

In this section, the proposed model is first validated through two cases of hydraulic fracture propagation. Then, the influences of rock plastic deformation and permeability on hydraulic fracture propagation in deep reservoirs are discussed. Finally, the proposed model is extended to simulate the simultaneous propagation of multiple hydraulic fractures.

\subsection{Model Verification}

Since no analytical solution of elasto-plastic hydraulic fracture propagation can be referred to, the correctness and effectiveness of the presented model and algorithm are verified from the following two aspects: (1) fracture propagation under the elastic deformationKGD model, and (2) fracture propagation under plastic deformation-ABAQUS.

\subsubsection{Fracture Propagation under Elastic Deformation}

Neglecting the plastic deformation and matrix flow, the proposed model is simplified to the classical KGD problem [6,7]. The numerical results are now compared with the existing analytical solutions under elastic deformation. The input parameters are set as follows: $E=25 \mathrm{GPa}, v=0.2, t_{c}=0.5 \mathrm{MPa}, G_{C}=50 \mathrm{~N} / \mathrm{m}, Q_{\text {inject }}=0.0005 \mathrm{~m}^{3} / \mathrm{s}$, and $\mu=0.1 \mathrm{~Pa} \cdot \mathrm{s}$. Figure 5 shows the comparisons of the fracture half-length and the fracture width at wellbore between the numerical solutions and analytical solutions [45]. It can be found that the numerical results agree well with the analytical solutions. 


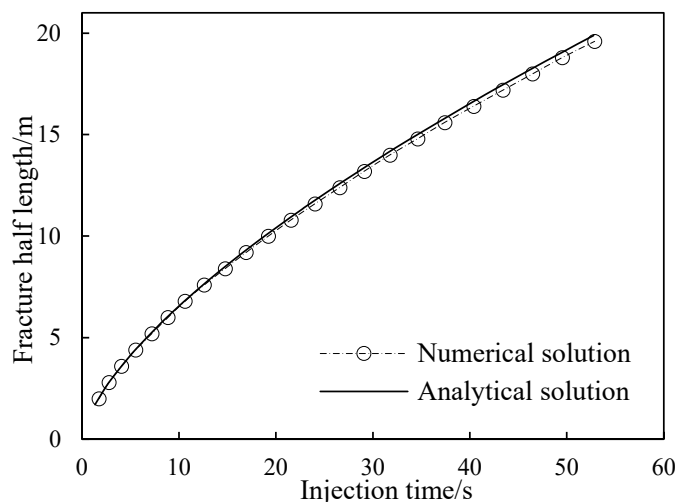

(a)

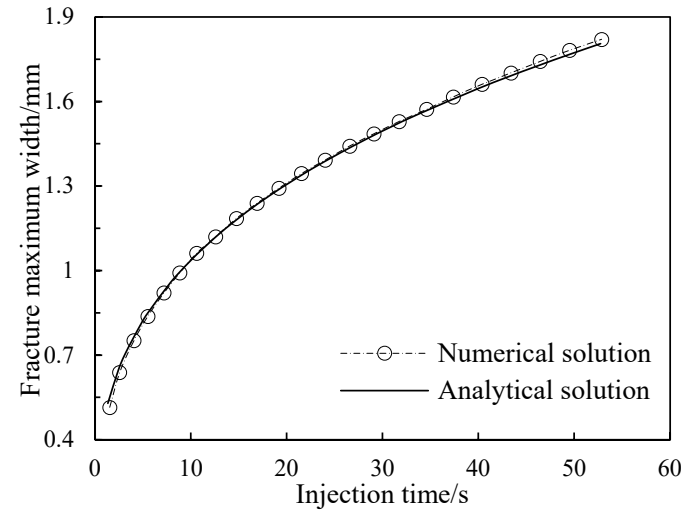

(b)

Figure 5. Analytical and numerical results. (a) Fracture half length, and(b) fracture maximum width.

\subsubsection{Fracture Propagation under Plastic Deformation}

Another case is carried out to simulate hydraulic fracture propagation in the deep reservoir $(100 \mathrm{~m} \times 100 \mathrm{~m})$. As shown in Figure 6, only half of the domain is simulated based on the symmetry of the problem, and the hydraulic fracture propagates along the direction of the maximum horizontal principal stress. To verify the efficiency of the proposed method for modeling fracture propagation under plastic deformation, obtained solutions by the proposed EDFM-XFEM model are compared with the results of the finite element model proposed by Wang [31] and solved by ABAQUS, a commercial software. The grids used for the simulations are also shown in Figure 6. The grids of the finite element model are refined near the fracture, and the matrix grid count is 32,630 . On the other hand, uniform grids $(125 \times 74)$ are used for the proposed EDFM-XFEM model. The input parameters are as follows: $E=15 \mathrm{GPa}, v=0.25, \varphi=30^{\circ}, \psi=10^{\circ}, c=3.5 \mathrm{MPa}, k_{m}=10 \mathrm{mD}, \varphi=0.1, \alpha=1$, $t_{c}=1 \mathrm{MPa}, G_{C}=2000 \mathrm{~N} / \mathrm{m}, \mu=10 \mathrm{mPa} \cdot \mathrm{s}, \rho_{l}=1000 \mathrm{~kg} / \mathrm{m}^{3}$, and $Q_{\text {inject }}=0.001 \mathrm{~m}^{3} / \mathrm{s}$. The initial pore pressure is $30 \mathrm{MPa}$ and the perforation depth is $2 \mathrm{~m}$.

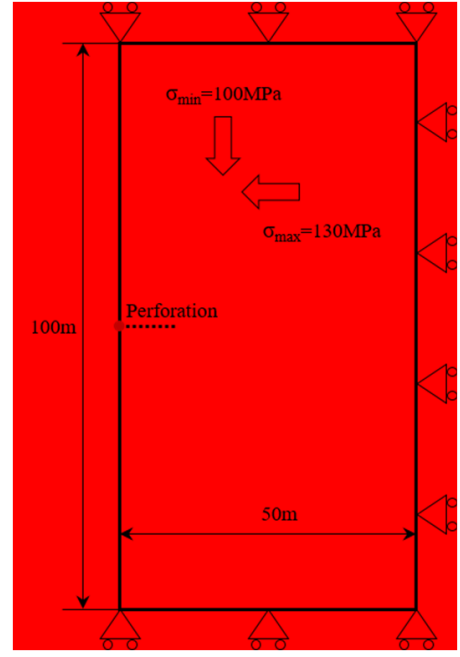

(a)

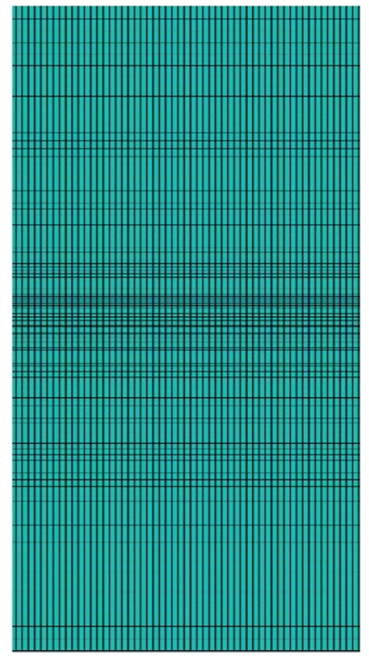

(b)

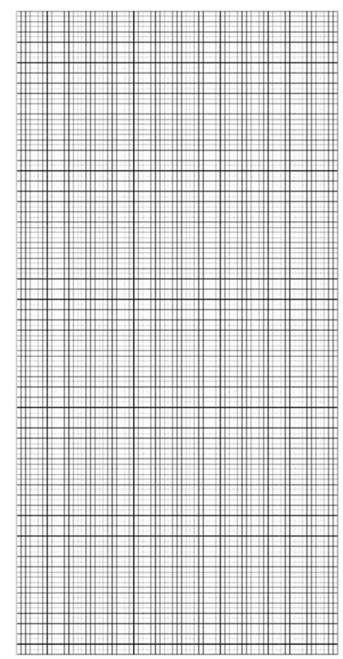

(c)

Figure 6. Schematic of the numerical model. (a) Geometry; (b) grids used for FEM-ABAQUS; and (c) grids used for proposed EDFM-XFEM model.

The distributions of displacement and stress solved by the two models are compared, as shown in Figures 7 and 8. It can be found that the results based on the two different 
models show good agreement, which demonstrates the accuracy of the proposed EDFMXFEM model for modeling fracture propagation under plastic deformation. The difference between the EDFM-XFEM model and the finite element model is that the latter must use the conforming mesh, while the former can use the non-matching mesh. Therefore, for the finite element model, the hydraulic fracture can only extend along the grid boundary and only straight fracture propagation can be simulated. The EDFM-XFEM model can simulate planar or non-planar hydraulic fracture propagation in structured grids without remeshing.



(a)

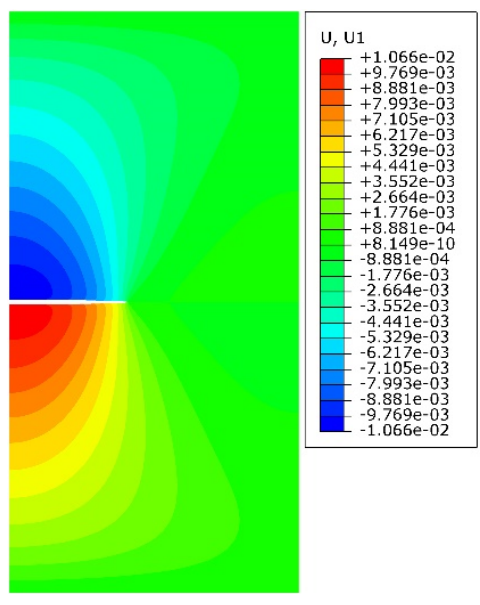

(b)

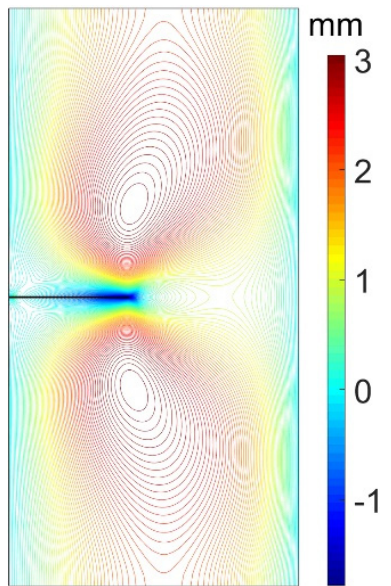

(c)

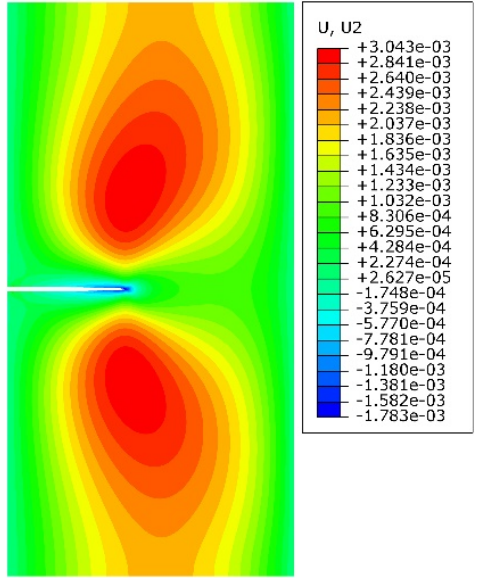

(d)

Figure 7. Distribution of displacement $\left(\mathrm{t}=3.58 \times 10^{2} \mathrm{~s}\right)$ : (a) $\mathrm{u} \_y y$ by EDFM-XFEM model; $(\mathbf{b}) \mathrm{u} \_y y$ by FEM model; $(\mathbf{c}) \mathrm{u} \_x \mathrm{x}$

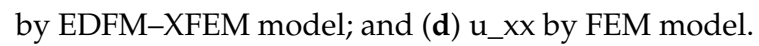

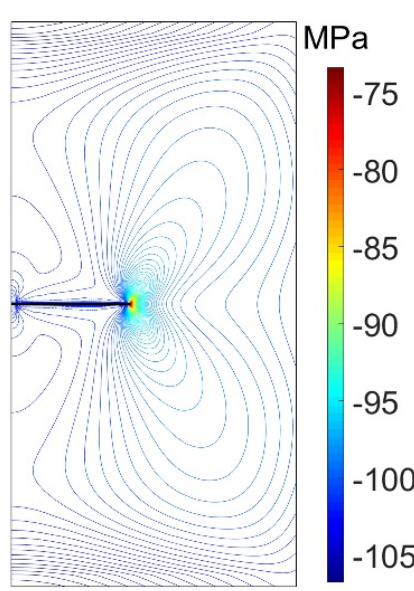

(a)

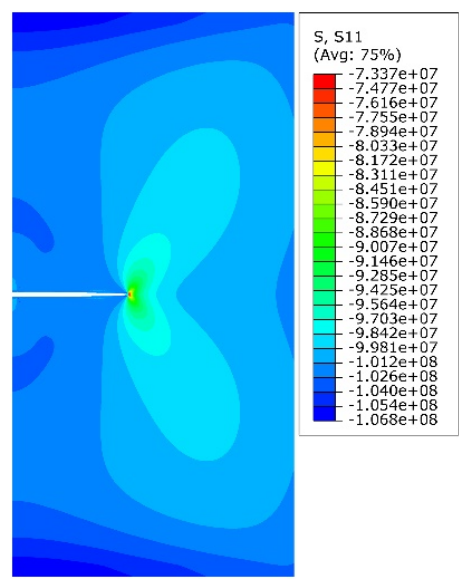

(b)

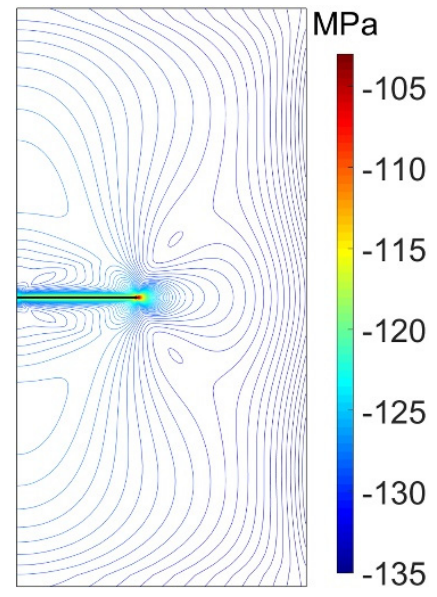

(c)

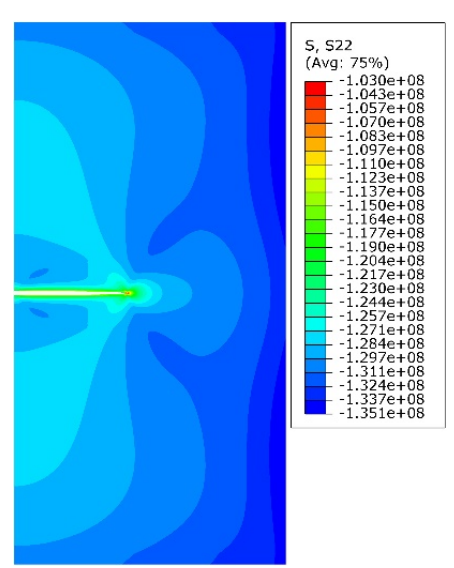

(d)

Figure 8. Distribution of stress $\left(\mathrm{t}=3.58 \times 10^{2} \mathrm{~s}\right)$ : (a) sigma_yy by EDFM—XFEM model; (b) sigma_yy by FEM model; (c) sigma_xx by EDFM-XFEM model; and (d) sigma_xx by FEM model.

\subsection{Results and Discussion}

Next, a series of numerical cases are performed to investigate the influences of rock plasticity, internal friction angle, dilatancy angle and permeability on hydraulic fracture propagation. In addition, the proposed model is extended to simulate multiple hydraulic fracture propagations. 


\subsubsection{Evolution of Plastic Zone}

As shown in Figure 8, it can be found that the area with the large stress change appears near the fracture tip, so the stress concentration occurs at the fracture tip. Figure 9 displays the evolution of the plastic zone during elasto-plastic hydraulic fracture propagation for the simulation case in Section 4.1.2. It can be observed that plastic zones appear around the fracture tip owing to the stress concentration. Besides, with the extension of the hydraulic fracture, unloading occurs behind the advancing tip and new plastic zones are formed around the new tip, so the plastic zone moves forward. Meanwhile, plastic strain accumulates around the fracture walls as illustrated in Figure 10.

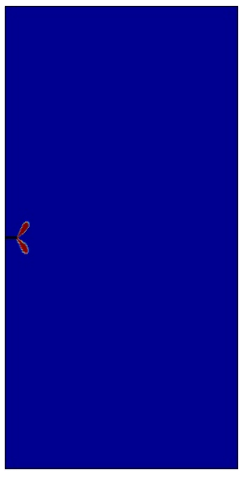

(a)

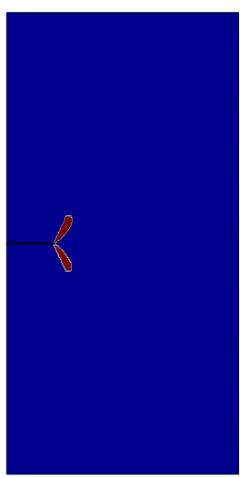

(b)

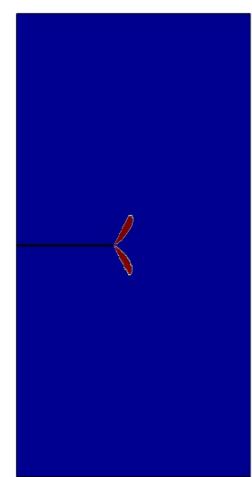

(c)

Figure 9. Evolutions of plastic zone during hydraulic fracturing after the following times: (a) $1.6 \times 10^{1} \mathrm{~s}$; (b) $1.23 \times 10^{2} \mathrm{~s}$; and (c) $3.58 \times 10^{2} \mathrm{~s}$.

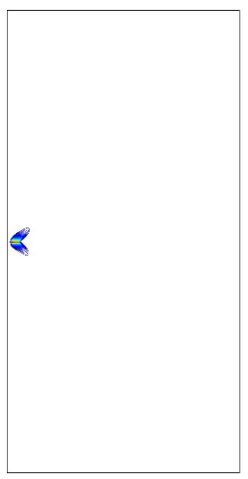

(a)

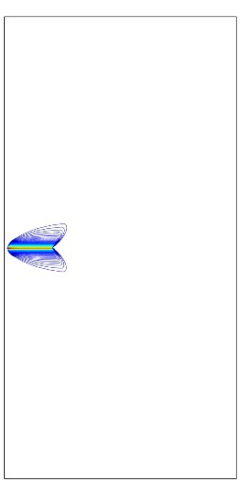

(b)

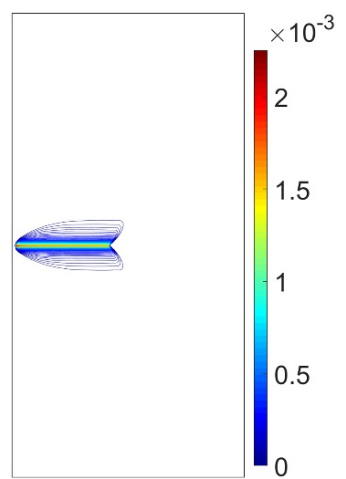

(c)

Figure 10. Contours of accumulative equivalent plastic strain after the following times: (a) $1.6 \times 10^{1} \mathrm{~s} ;(\mathbf{b}) 1.23 \times 10^{2} \mathrm{~s}$; and (c) $3.58 \times 10^{2} \mathrm{~s}$.

\subsubsection{Effect of Plastic Deformation}

To analyze the effects of plastic deformation on the hydraulic fracturing process, the simulation case in Section 4.1.2 is performed again without considering rock plasticity. Figure 11 shows the comparisons of the fracture width profiles, fracture width at wellbore, fracture half-length and net pressure at wellbore. Figure 11a displays the comparison of the fracture width profiles for the same fracture length. The result shows that the opening of the elasto-plastic hydraulic fractures is larger than that of the elastic hydraulic fractures. Besides, as can be seen, the initial fracture length is memorized in the fracture width profile for the elasto-plastic hydraulic fracture, since no plastic deformation is associated with the initial fracture (as shown in Figure 10). The comparisons of the fracture width at wellbore and the fracture half-length are presented in Figure $11 b, c$, which indicate that the 
elasto-plastic hydraulic fractures are wider and shorter than the elastic hydraulic fractures at the same injection time. Figure 11d demonstrates that the fluid pressure required for the propagation of elasto-plastic fractures is higher than that of elastic fractures. As rock plasticity results in higher energy dissipation in deep reservoirs, larger pressure is required for fracture extension, which leads to hydraulic fractures with larger openings. Meanwhile, corresponding to the mass conservation law, a larger opening means a smaller length, so the extension speed of elasto-plastic fractures is lower than that of elastic fractures. Therefore, to obtain the desired fracture length, larger injection volumes and higher injection pressures are needed for hydraulic fracturing in deep reservoirs.

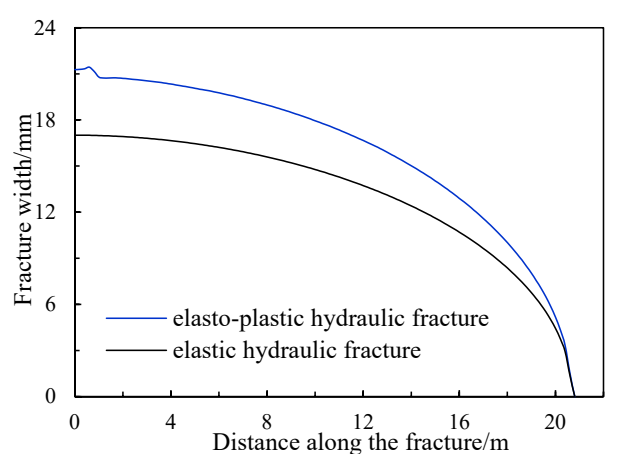

(a)

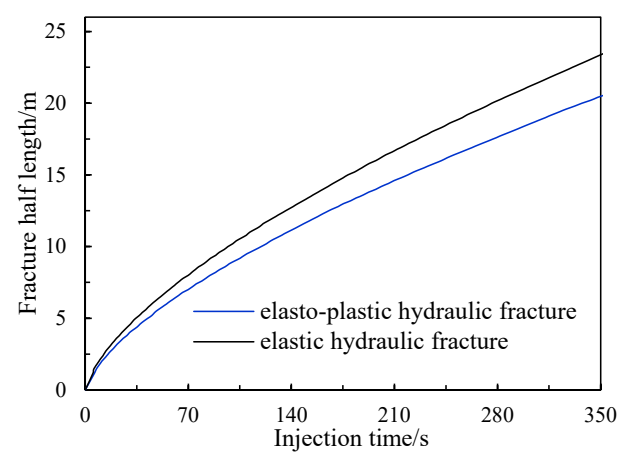

(c)

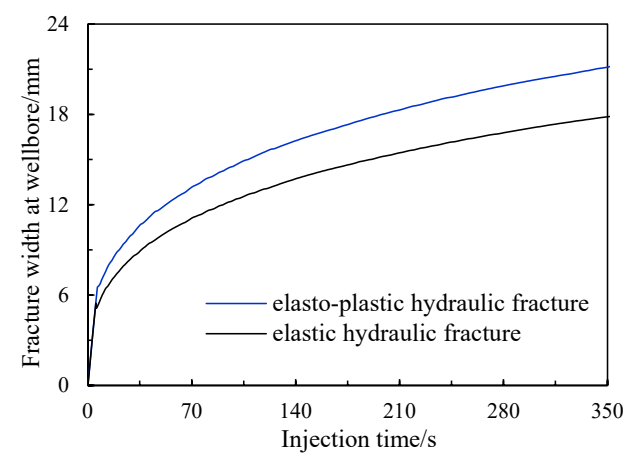

(b)

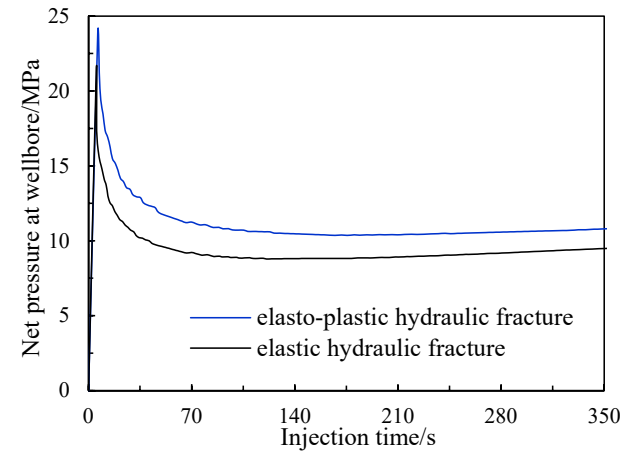

(d)

Figure 11. Comparison between elasto-plastic and elastic hydraulic fracture. (a) Fracture width profiles for same fracture length; (b) fracture width at wellbore; (c) fracture half-length; and (d) net pressure at wellbore.

Further, the sensitivities of the two plastic parameters involved in the elasto-plastic tangent stiffness tensor $\mathbf{D}_{e p}$, internal friction angle $\varphi$, and dilatancy angle $\psi$ are studied. The numerical simulation case in Section 4.1.2 is conducted again with the parameters remaining unchanged, except the internal friction angle which is set as $30^{\circ}, 35^{\circ}$ and $40^{\circ}$. Figure 12 displays the numerical results for the fracture width, fracture length and net pressure with different values of $\varphi$. As can be seen, with the increase in $\varphi$, the fracture width and injection fluid pressure decrease while the fracture half-length increases, which means the effect of rock plasticity on hydraulic fracturing is weakened as the internal friction angle increases. Then, to study the effects of the dilatancy angle $\psi$, the internal friction angle is fixed at $30^{\circ}$ while the values of $\psi$ are set as $10^{\circ}, 15^{\circ}$ and $20^{\circ}$. The numerical results are provided in Figure 13. The results show that the fracture width and injection fluid pressure decrease while the fracture half-length increases with the decrease in the dilatancy angle, which means the effect of the dilatancy angle on hydraulic fracturing is opposite to that of the internal friction angle. Compared with the latter, the former has little influence on hydraulic fracturing. 


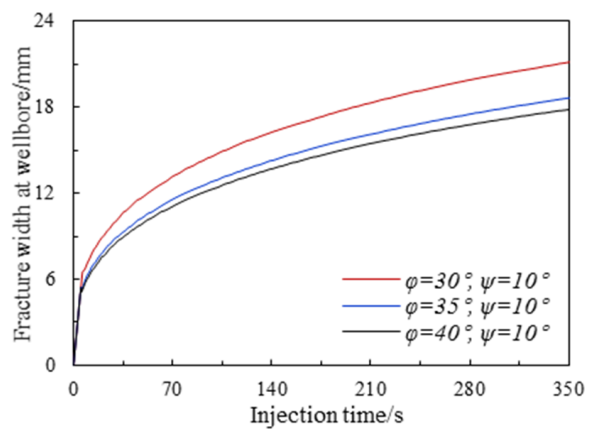

(a)

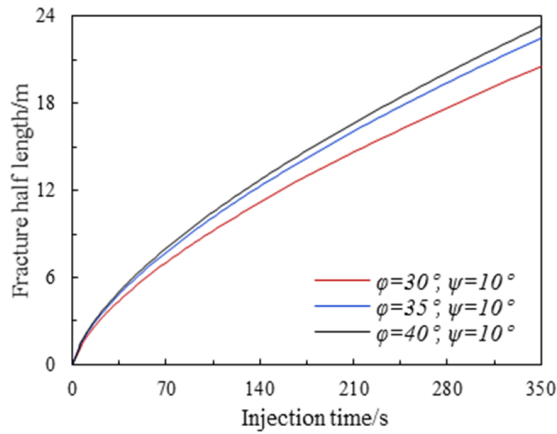

(b)

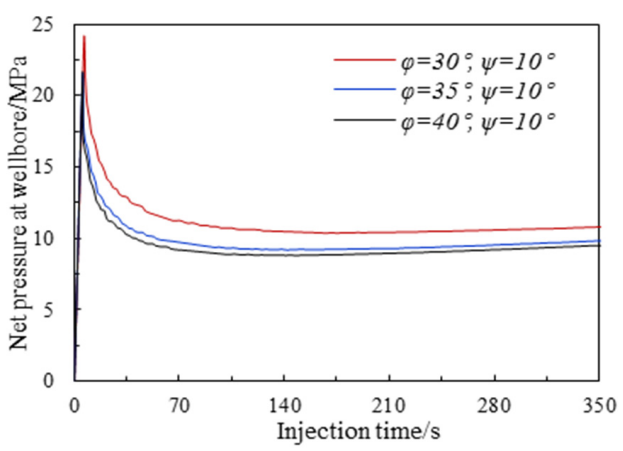

(c)

Figure 12. Numerical results with different internal friction angles. (a) Fracture width at wellbore; (b) fracture half-length; and (c) net pressure at wellbore.

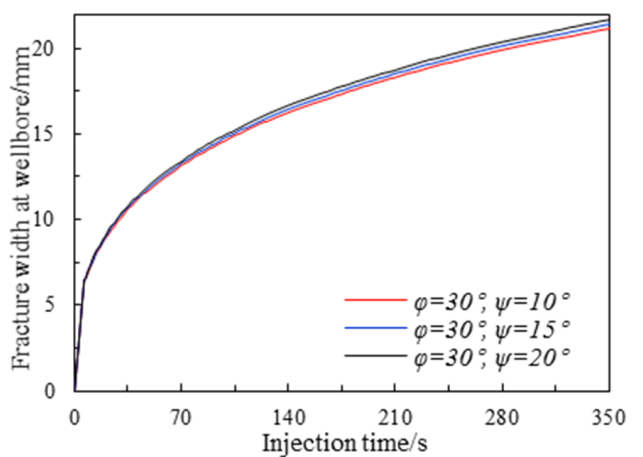

(a)

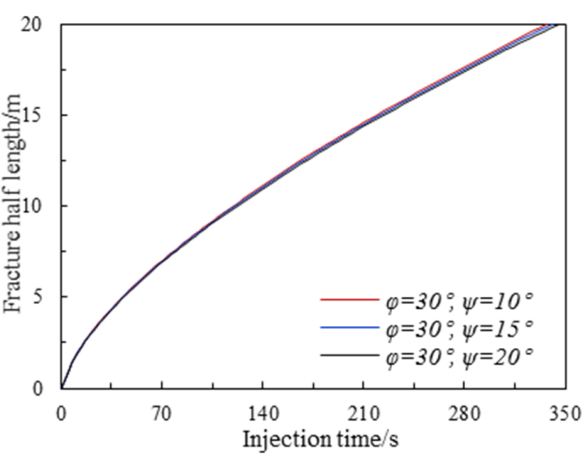

(b)

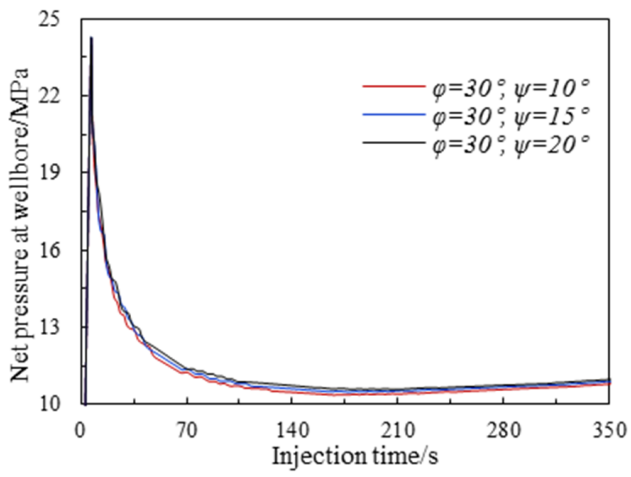

(c)

Figure 13. Numerical results with different dilatancy angles. (a) Fracture width at wellbore; (b) fracture half-length; and (c) net pressure at wellbore. 


\subsubsection{Effect of Permeability}

In this part, we investigate the influences of permeability on the hydraulic fracturing process. The numerical simulation case in Section 4.1.2 is carried out again with the input parameters unchanged, except the matrix permeability $k_{m}$, whose value varies from $5 \mathrm{mD}$ to $20 \mathrm{mD}$. Figure 14 displays the distribution of pore pressure in the matrix with different permeabilities. It can be found that when the matrix permeability is low, a low pressure zone exists in front of the fracture tip. As the value of the matrix permeability increases, the pressure waves propagate outward in an approximate round shape and the low pressure zone gradually disappears. Figure 15 provides the variation in the fracture width at wellbore and the fracture half-length obtained with different values of matrix permeability. One can see that at the same injection time, as the value of matrix permeability increases, the fracture width and fracture half-length decrease. This is because, with the increase in matrix permeability, more fracturing fluid leaks into the matrix, which leads to a shorter and narrower hydraulic fracture.

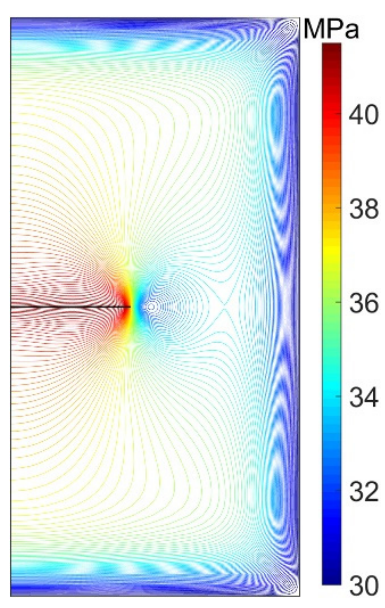

(a)

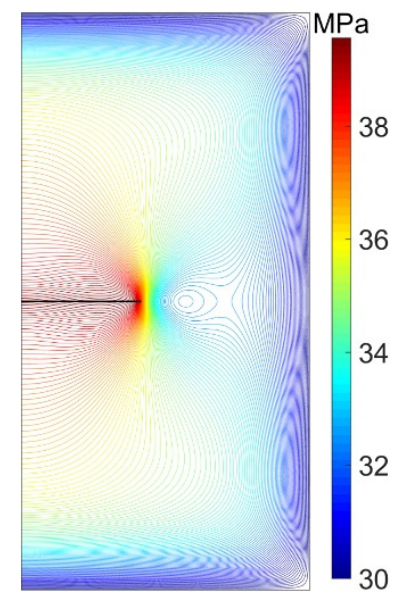

(b)

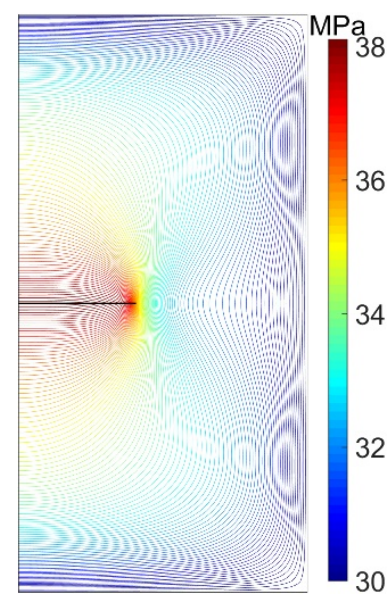

(c)

Figure 14. Contours of pore pressure in matrix $(t=358 \mathrm{~s}):(\mathbf{a}) k_{m}=5 \mathrm{mD}$; (b) $k_{m}=10 \mathrm{mD}$; and (c) $k_{m}=20 \mathrm{mD}$.

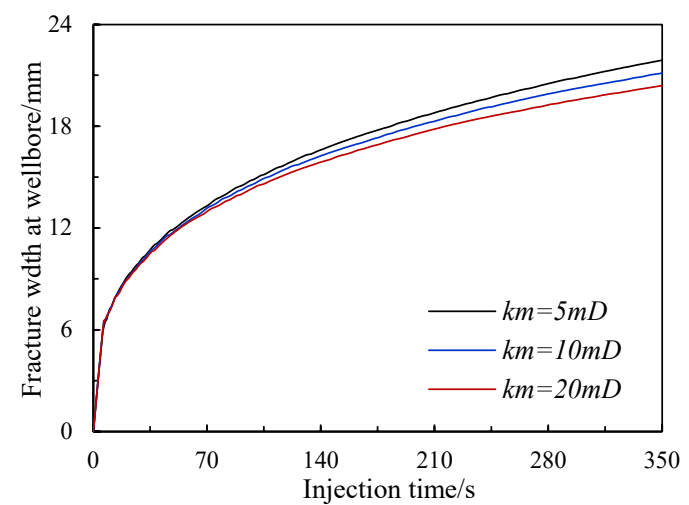

(a)

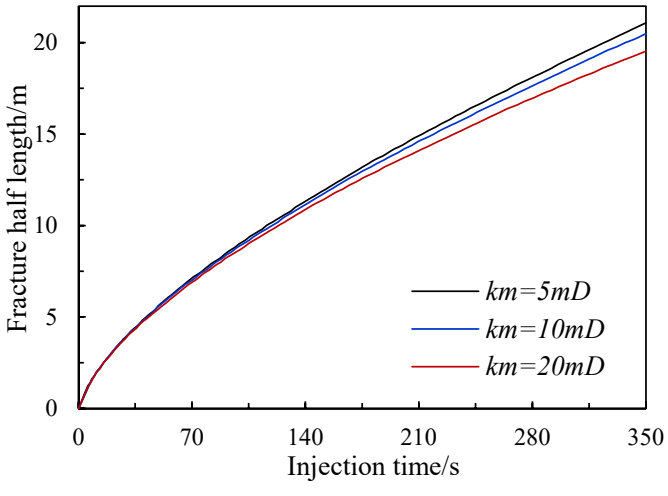

(b)

Figure 15. Numerical results with different permeabilities. (a) Fracture width at wellbore, and(b) fracture half-length. 


\subsubsection{Extension to Multiple Hydraulic Fractures Propagation}

In the above cases, only a single straight fracture is simulated. To investigate the effect of rock plasticity on the propagation path of non-planar fractures, two hydraulic fracture propagations in poro-elastic media and poro-elasto-plastic media are performed in this part. The fracture spacing is $5 \mathrm{~m}$. The other model settings and parameters remain unchanged, except the horizontal stress difference which is reduced to $5 \mathrm{MPa}$. Figure $16 \mathrm{a}, \mathrm{b}$ show the comparisons of the fracture widths. It is obvious that when considering plastic deformation, hydraulic fractures with a larger opening and smaller length are obtained, which is consistent with the conclusion of single hydraulic fracture propagation in Section 4.2.2. The comparison of fracture trajectories is shown in Figure 16c. It is interesting to find that the deflection of fracture direction in poro-elastic meida is smaller than that in poro-elastoplastic media, meaning that the stress-shadowing effect is enhanced when considering the plastic deformation. A possible explanation is that a larger fracture width leads to larger induced stress, which causes fractures to apply larger normal stresses to each other, thus the stress-shadowing effect is enhanced.

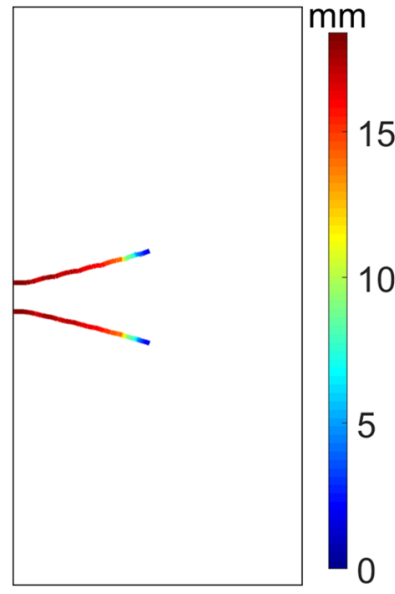

(a)

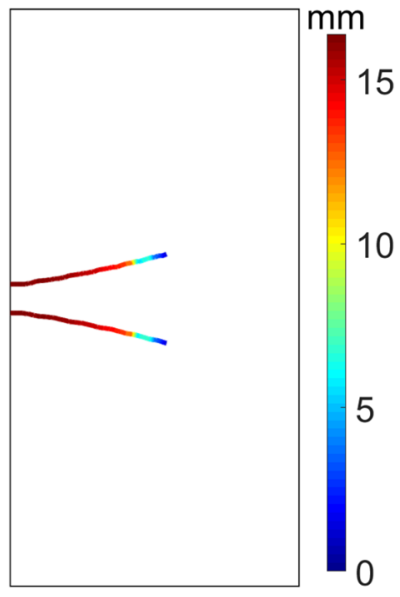

(b)

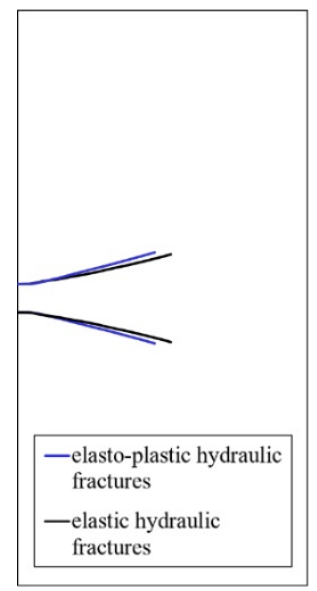

(c)

Figure 16. Comparison of fracture width and trajectories. (a) Elasto-plastic fracture width; (b) elastic fracture width; and (c) fracture trajectories.

\section{Conclusions}

In this paper, a hybrid numerical model has been proposed to simulate elasto-plastic hydraulic fracture propagation in deep reservoirs. Based on the proposed model, the poroelasto-plastic effects during hydraulic fracturing in the deep reservoir are investigated, as follows:

1. During hydraulic fracturing in deep reservoirs, rock plasticity results in higher energy dissipation in deep reservoirs, larger pressure is required for fracture extension, which leads to hydraulic fractures with larger openings. Therefore, larger injection volume and higher injection pressure are needed to obtain the desired fracture length;

2. As the internal friction angle increases from $30^{\circ}$ to $40^{\circ}$, the fracture width and injection pressure decrease while the fracture propagation velocity increases, which means the effect of plastic deformation is weakened. The effects of the dilatancy angle on hydraulic fracturing are opposite to that of the internal friction angle;

3. As the matrix permeability increases from $5 \mathrm{mD}$ to $20 \mathrm{mD}$, more fracturing fluid leaks into the matrix, leading to a shorter and narrower hydraulic fracture;

4. For two hydraulic fracture propagations in deep reservoirs, plastic deformation can enhance the stress-shadowing effect. 
Author Contributions: Conceptualization, J.Y. and W.L.; methodology, W.L.; validation, W.L. and Q.Z.; writing-original draft preparation, W.L., Q.Z., Z.L. and T.L.; supervision, J.Y., Q.Z. and X.Y.; funding acquisition, J.Y., Q.Z. and X.Y. All authors have read and agreed to the published version of the manuscript.

Funding: This research was funded by the National Natural Science Foundation of China (grant nos. 51904321 and 52034010), the Innovation Project of China University of Petroleum (grant no. YCX2019011), the Fundamental Research Funds for the Central Universities (20CX06025A) and the Qingdao Postdoctoral Applied Research Project (QDYY20190025).

Data Availability Statement: The data presented in this paper are available on request from the corresponding author.

Acknowledgments: The first author would also like to appreciate the China Scholarship Council (no. 201906450093) for funding his study at the University of Lille.

Conflicts of Interest: The authors declare no conflict of interest.

\section{References}

1. Pang, X.; Jia, C.; Wang, W. Petroleum geology features and research developments of hydrocarbon accumulation in deep petroliferous basins. Pet. Sci. 2015, 12, 1-53. [CrossRef]

2. Yao, J.; Huang, Z.; Liu, W.; Zhang, Y.; QingDong, Z.; Yan, X. Key mechanical problems in the development of deep oil and gas reservoirs. Sci. Sin. Phys. Mech. Astron. 2018, 48, 044701.

3. Olson, J. Multi-fracture propagation modeling: Applications to hydraulic fracturing in shales and tight gas sands. In Proceedings of the 42nd US Rock Mechanics Symposium (USRMS), San Francisco, CA, USA, 29 June-2 July 2008.

4. Chen, M. Review of study on rock mechanics at great depth and its applications to petroleum engineering of china. Chin. J. Rock Mech. Eng. 2004, 14, 2455-2462.

5. Sone, H.; Zoback, M. Visco-plastic properties of shale gas reservoir rocks. In Proceedings of the 45th US Rock Mechanics/Geomechanics Symposium, San Francisco, CA, USA, 26-29 June 2011.

6. Khristianovic, S.; Zheltov, Y. Formation of vertical fractures by means of highly viscous fluids. In Proceedings of the 4th World Petroleum Congress, Rome, Italy, 6-15 June 1955; pp. 579-586.

7. Geertsma, J.; De Klerk, F. A rapid method of predicting width and extent of hydraulically induced fractures. J. Pet. Technol. 1969, 21, 571-581. [CrossRef]

8. Perkins, T.; Kern, L. Widths of hydraulic fractures. J. Pet. Technol. 1961, 13, 937-949. [CrossRef]

9. Nordgren, R. Propagation of a vertical hydraulic fracture. Soc. Pet. Eng. 1972, 12, 306-314. [CrossRef]

10. Cleary, M.P. Comprehensive design formulae for hydraulic fracturing. In Proceedings of the SPE Annual Technical Conference and Exhibition, Dallas, TX, USA, 21-24 September 1980.

11. Bouteca, M. 3D analytical model for hydraulic fracturing: Theory and field test. In Proceedings of the SPE Annual Technical Conference and Exhibition, Houston, TX, USA, 17 September 1984.

12. Sarris, E.; Papanastasiou, P. Modeling of hydraulic fracturing in a poroelastic cohesive formation. Int. J. Geomech. 2011, 12, 160-167. [CrossRef]

13. Carrier, B.; Granet, S. Numerical modeling of hydraulic fracture problem in permeable medium using cohesive zone model. Eng. Fract. Mech. 2012, 79, 312-328. [CrossRef]

14. Lecampion, B. An extended finite element method for hydraulic fracture problems. Commun. Numer. Methods Eng. 2009, 25, 121-133. [CrossRef]

15. Simpson, R.; Trevelyan, J. A partition of unity enriched dual boundary element method for accurate computations in fracture mechanics. Comput. Methods Appl. Mech. Eng. 2011, 200, 1-10. [CrossRef]

16. $\mathrm{Wu}, \mathrm{K} . ;$ Olson, J.E. Simultaneous multifracture treatments: Fully coupled fluid flow and fracture mechanics for horizontal wells. SPE J. 2015, 20, 337-346. [CrossRef]

17. Torres, S.A.G.; Castaño, J.D.M. Simulation of the hydraulic fracture process in two dimensions using a discrete element method. Phys. Rev. E 2007, 75, 066109. [CrossRef]

18. Damjanac, B.; Cundall, P. Application of distinct element methods to simulation of hydraulic fracturing in naturally fractured reservoirs. Comput. Geotech. 2016, 71, 283-294. [CrossRef]

19. Nikolic, M.; Ibrahimbegovic, A.; Miscevic, P. Discrete element model for the analysis of fluid-saturated fractured poro-plastic medium based on sharp crack representation with embedded strong discontinuities. Comput. Methods Appl. Mech. Eng. 2016, 298, 407-427. [CrossRef]

20. Nikolić, M.; Karavelić, E.; Ibrahimbegovic, A.; Miščević, P. Lattice Element Models and Their Peculiarities. Arch. Comput. Methods Eng. 2018, 25, 753-784. [CrossRef]

21. Meyer, B.R.; Bazan, L.W. A discrete fracture network model for hydraulically induced fractures-theory, parametric and case studies. In Proceedings of the SPE Hydraulic Fracturing Technology Conference, The Woodlands, TX, USA, $24-26$ January 2011. 
22. Fu, P.; Johnson, S.M.; Carrigan, C.R. An explicitly coupled hydro-geomechanical model for simulating hydraulic fracturing in arbitrary discrete fracture networks. Int. J. Numer. Anal. Methods Geomech. 2013, 37, 2278-2300. [CrossRef]

23. Liu, W.; Zeng, Q.; Yao, J. Numerical simulation of elasto-plastic hydraulic fracture propagation in deep reservoir coupled with temperature field. J. Pet. Sci. Eng. 2018, 171, 115-126. [CrossRef]

24. Lecampion, B.; Bunger, A.; Zhang, X. Numerical methods for hydraulic fracture propagation: A review of recent trends. J. Nat. Gas Sci. Eng. 2018, 49, 66-83. [CrossRef]

25. Weng, X. Modeling of complex hydraulic fractures in naturally fractured formation. J. Unconv. Oil Gas Resour. 2015, 9, 114-135. [CrossRef]

26. Papanastasiou, P. An efficient algorithm for propagating fluid-driven fractures. Comput. Mech. 1999, 24, 258-267. [CrossRef]

27. Liu, F.; Gordon, P.; Meier, H.; Valiveti, D. A stabilized extended finite element framework for hydraulic fracturing simulations. Int. J. Numer. Anal. Methods Geomech. 2017, 41, 654-681. [CrossRef]

28. Zeng, Q.D.; Yao, J.; Shao, J.F. Effect of plastic deformation on hydraulic fracturing with extended element method. Acta Geotech 2019, 14, 2083-2101. [CrossRef]

29. Adachi, J.; Siebrits, E.; Peirce, A.; Desroches, J. Computer simulation of hydraulic fractures. Int. J. Rock Mech. Min. Sci. 2007, 44, 739-757. [CrossRef]

30. Sarris, E.; Papanastasiou, P. Numerical modeling of fluid-driven fractures in cohesive poroelastoplastic continuum. Int. J. Numer. Anal. Methods Geomech. 2013, 37, 1822-1846. [CrossRef]

31. Wang, H.; Marongiu-Porcu, M.; Economides, M.J. Poroelastic and poroplastic modeling of hydraulic fracturing in brittle and ductile formations. SPE Prod. Oper. 2016, 31, 47-59. [CrossRef]

32. Yan, X.; Huang, Z.; Yao, J.; Li, Y.; Fan, D. An efficient embedded discrete fracture model based on mimetic finite difference method. J. Pet. Sci. Eng. 2016, 145, 11-21. [CrossRef]

33. Yan, X.; Huang, Z.; Yao, J.; Li, Y.; Fan, D.; Zhang, K. An efficient hydro-mechanical model for coupled multi-porosity and discrete fracture porous media. Comput. Mech. 2018, 62, 943-962. [CrossRef]

34. Zeng, Q.; Liu, W.; Yao, J. Hydro-mechanical modeling of hydraulic fracture propagation based on embedded discrete fracture model and extended finite element method. J. Pet. Sci. Eng. 2018, 167, 64-77. [CrossRef]

35. Zeng, Q.; Yao, J.; Shao, J. Study of hydraulic fracturing in an anisotropic poroelastic medium via a hybrid EDFM-XFEM approach. Comput. Geotech. 2019, 105, 51-68. [CrossRef]

36. Biot, M.A. General theory of three-dimensional consolidation. J. Appl. Phys. 1941, 12, 155-164. [CrossRef]

37. De Souza Neto, E.A.; Peric, D.; Owen, D.R.J. Computational Methods for Plasticity: Theory and Applications; Wiley: Chichester, UK, 2011.

38. Papanastasiou, P. The influence of plasticity in hydraulic fracturing. Int. J. Fract. 1997, 84, 61-79. [CrossRef]

39. Chen, Z.; Bunger, A.; Zhang, X.; Jeffrey, R.G. Cohesive zone finite element-based modeling of hydraulic fractures. Acta Mech. Solida Sin. 2009, 22, 443-452. [CrossRef]

40. Mohammadnejad, T.; Khoei, A. An extended finite element method for hydraulic fracture propagation in deformable porous media with the cohesive crack model. Finite Elem. Anal. Des. 2013, 73, 77-95. [CrossRef]

41. Mohammadnejad, T.; Khoei, A. Hydro-mechanical modeling of cohesive crack propagation in multiphase porous media using the extended finite element method. Int. J. Numer. Anal. Methods Geomech. 2013, 37, 1247-1279. [CrossRef]

42. Kim, J.; Tchelepi, H.A.; Juanes, R. Stability and convergence of sequential methods for coupled flow and geomechanics: Fixedstress and fixed-strain splits. Comput. Methods Appl. Mech. Eng. 2011, 200, 1591-1606. [CrossRef]

43. Mikelić, A.; Wang, B.; Wheeler, M.F. Numerical convergence study of iterative coupling for coupled flow and geomechanics. Comput. Geosci. 2014, 18, 325-341. [CrossRef]

44. Simo, J.; Taylor, R. A return mapping algorithm for plane stress elastoplasticity. Int. J. Numer. Methods Eng. 1986, 22, 649-670. [CrossRef]

45. Valko, P.; Economides, M.J. Hydraulic Fracture Mechanics; Wiley: Chichester, UK, 1995; Volume 28. 